actually occurred. Thus, Elschnig himself did not experience this mishap neither did it occur in his department - at least not between 1912 and 1932, to my knowledge.

My suggestion is to cut the lashes of every patient's eye to be operated on, the day before the operation, or even two days previous to the operation. This can be done in the ward or in the surgeon's office where all records are easily available and when-in the worst case-the patient may remind the assistant that he is preparing the wrong eye. In Elschnig's clinic, we used to cut the cilia in the preparation room adjacent to the operating room; for the last years, I have been cutting the lashes one or two days before surgery, in all intra-ocular operations. The same procedure could be adopted for the enucleation and will prevent the search for, and possible mistake of, the eye to be operated on.

With sincerest congratulations for the improved appearance of the Journal.

I remain, very truly yours,

2508, Auburn Avenue,

K. W. ASCHER, M.D.

Cincinnati 19 , OHio,

February 28, 1947.

\title{
OBITUARY
}

\section{SIR ARNOLD LAWSON, K.B.E.}

SIR ARNOLD LAWSON was the fourth of seven sons of George Lawson (1831-1903). George Lawson was a pupil of Sir William Bowman at King's College Hospital, and went to the Crimea as an Assistant Surgeon in 1854. In May, 1855, he had a very severe attack of typhus fever that produced a complete paraplegia, and he was invalided out of the Army in January, 1856. He was already an Assistant Surgeon at Middlesex Hospital where he was a colleague of John Whitaker Hulke. George Lawson was elected Assistant Surgeon to Moorfields Eye Hospital in 1862 on the same day as Sir Jonathan Hutchinson.

He became Surgeon-Oculist to Queen .Victoria, holding this appointment until her death in 1901 .

$\mathrm{He}$ was a man of great charm, a Tractarian, deeply religious, whose generosity, especially to his hospital patients, has become legendary. To follow such a distinguished father is a heavy task, and this Sir Arnold did in detail except that he confined the professional side of his life to ophthalmology. 
He was born at 12, Harley Street (into which his father had moved in 1863) on December 4, 1867, and he was destined to spend his whole life there. He was educated at the Merchant Taylors School and in 1886 entered the Medical School at Middlesex Hospital as Senior Entrance Scholar. He did well as a student, winning the Hetley Prize in 1890 and was Senior Broderip Scholar in 1891, in which year he qualified. He graduated as M.D. of Brussels in 1891 and obtained his F.R.C.S. diploma in 1893.

Sir Arnold soon decided to be an ophthalmic surgeon and joined his father in practice. He was eleoted ophthalmic surgeon to the Paddington Green Children's Hospital in 1896 after having worked with Sir John Tweedy at Moorfields. In 1900, when it was decided to increase the visiting staff at Moorfields from nine to twelve, he was elected Assistant Surgeon together with John Herbert Fisher and Percy Flemming. He became full surgeon in 1907 and retired in 1914, becoming Consulting Surgeon in 1923. In 1910 he joined William Lang at Middlesex as Assistant Surgeon, succeeding him as full surgeon in 1914. In 1932 he was elected Consulting Surgeon. He served as ophthalmic surgeon to the Hospital of St. John and St. Elizabeth, and from 1914 to 1919 was ophthalmic surgeon to King Edward VII Hospital for Officers. For many years up to the time of his death he was Consulting.Ophthalmic Surgeon to the Royal Hospital for Incurables at Putney and to the Royal Medical Benevolent College, Epsom.

In 1914 began his important work in connection with the founding of St. Dunstan's. He became principal ophthalmic adviser to Sir Arthur Pearson in this connection and remained Chairman of the Ophthalmic Advisory Committee until his death. For this work he was appointed K.B.E. in 1920.

In 1940 he was appointed Ophthalmic Consultant to the Navy. Of this he was very proud, refusing to take any fee for his services, saying that it was his contribution to the branch of the Forces in which his son served.

He became suddenly ill in 1918 and the nature of the complaint was not diagnosed. He recovered almost as suddenly but in July, 1921, the true nature of his ill-health became apparent when he had a serious breakdown and he spent six months in a sanatorium. After his return to work he gave up many of his appointments and for five years attended no meetings where many people were congregated. He seemed to have, recovered all his vigour so as to lead a busy life to the time of his death on January 19, 1947. He actually saw patients on December 19.

Sir Arnold became a member of the Ophthalmological Society in 1896 and after serving as a Vice-President became Treasurer in 1919, retaining the office until 1947 (when he was elected honorary 


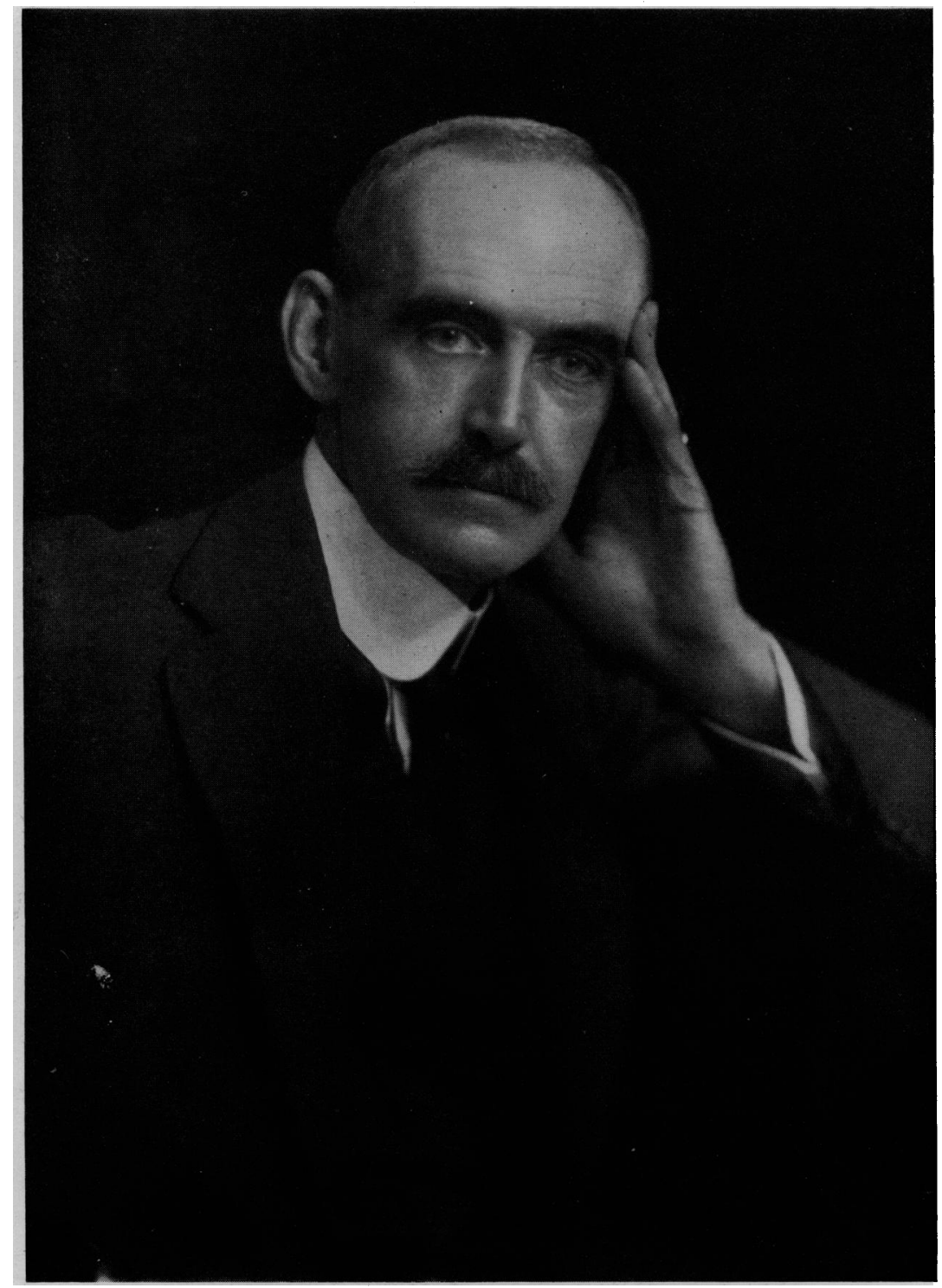

SIR ARNOLD LAWSON-1867-1947

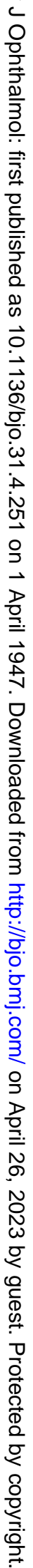


member), so that his resignation and death were reported at the same meeting of the Council. In this post he was very successful and the work interested him. He always said he hoped to hold the post for thirty years.

He became president of the Royal Medical Benevolent Fund on the death of Sir Thomas Barlow, and in this position proved a great success. His appeals, more especially the one at Christmas produced much greater funds than previously. He collected large sums for the completion and decoration of the Chapel at Middlesex Hospital in which his father and family had always taken a generous interest.

Lawson's literary output was not large when one considers the length of time he was in practice. He edited and largely re-wrote his father's text-book on Diseases and Injuries of the Eye, in 1903. He published a report on the War blind at St. Dunstan's in 1920; and wrote articles in Latham and English's System of Treatment. He published with Sir James Mackenzie Davidson a monograph on Treatment of the Eye by Radium.

He attended meetings of the Ophthalmological Society and the Ophthalmic Section of the Royal Society of Medicine, which he served as president from 1924 to 1926, taking part in discussions and occasionally reading papers.

Lawson will be much missed, ęspecially by his older colleagues. $\mathrm{He}$ was a well known figure to all, as he appeared every year for so long a time at the annual meetings of the Ophthalmological Society to present the treasurer's report.

The funeral took place at All Saints Church, Margaret Street, in the presence of a large representative congregation. He had been connected with All Saints from his earliest years and claimed to have been one of the oldest members of the congregation. He had displayed as a boy his love of music, and especially of church music. He was a regular member of the congregation at the Sunday early services.

He married in 1904, Helen, daughter of Andrew Clark, F.R.C.S., of 71 , Harley Street, who was a surgeon to the Middlesex Hospital. She died in 1944 and they are survived by two sons and a daughter.

\section{DEWAN BAHADUR DR. K. KOMAN NAYAR}

W'E regret to announce the death of Dewan Bahadur Dr. K. Koman Nayar, D.O.M.S. at his home in Madras, on November 1, 1946. Dr. Koman Nayar was one of the leading ophthalmologists in India. He served at the Government Ophthalmic Hospital, Madras, in various capacities from 1912 to 1946 when he retired. He became assistant superintendent in December, 1918, and frequently acted 